UCRL-JC-134060

PREPRINT

\title{
Electron Field Emission from Undoped and Doped DLC Films
}

\author{
V.G. Litovchenko \\ A.A. Evtukh \\ N.I. Klyui \\ Yu. M. Litvin \\ S. Yu. Kudzinovsky \\ A.G. Chakhovskoi \\ T.E. Felter
}

This paper was prepared for submittal to the

Materials Research Society 1999 Spring Meeting

San Francisco, CA

April 5-9, 1999

\section{April 1999}

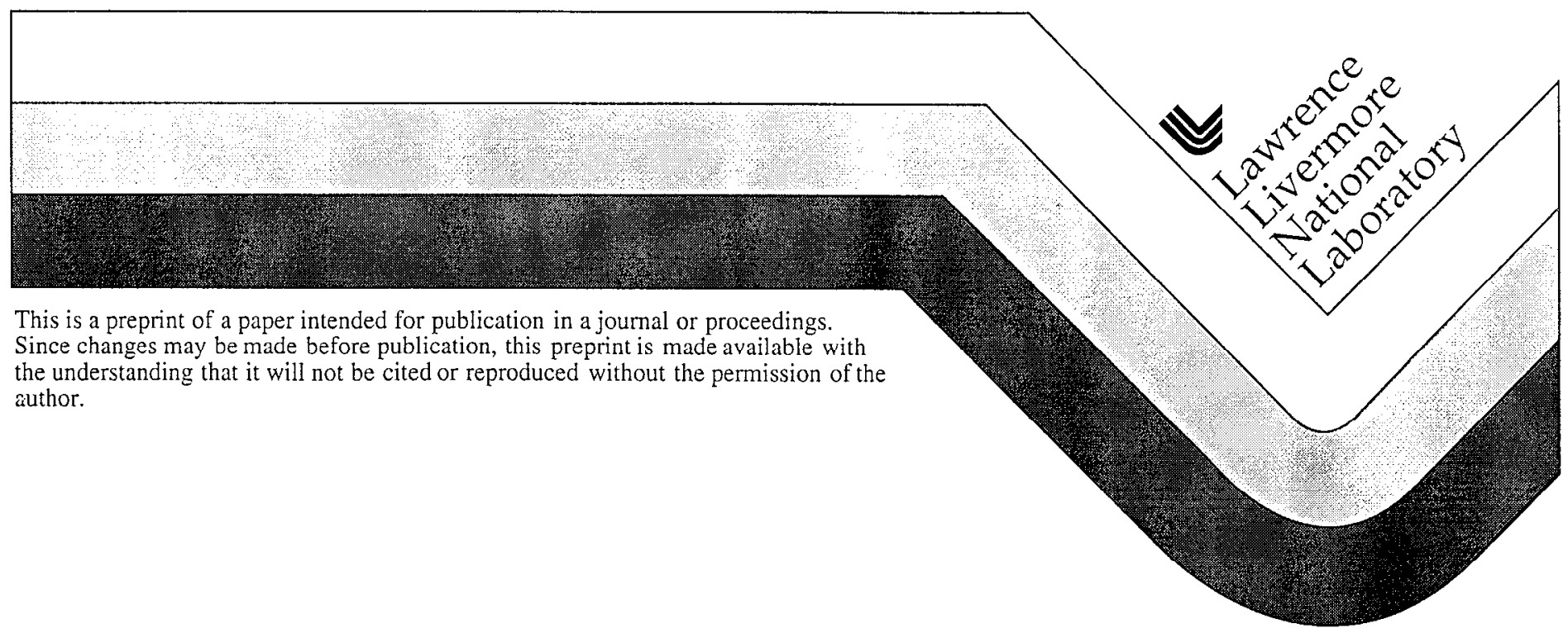




\section{DISCLAIMER}

This document was prepared as an account of work sponsored by an agency of the United States Government. Neither the United States Government nor the University of California nor any of their employees, makes any warranty, express or implied, or assumes any legal liability or responsibility for the accuracy, completeness, or usefulness of any information, apparatus, product, or process disclosed, or represents that its use would not infringe privately owned rights. Reference herein to any specific commercial product, process, or service by trade name, trademark, manufacturer, or otherwise, does not necessarily constitute or imply its endorsement, recommendation, or favoring by the United States Government or the University of California. The views and opinions of authors expressed herein do not necessarily state or reflect those of the United States Government or the University of California, and shall not be used for advertising or product endorsement purposes. 


\title{
ELECTRON FIELD EMISSION FROM UNDOPED AND DOPED DLC FILMS
}

\author{
V.G. LITOVCHENKO* , A.A. EVTUKH*, N.I. KLYUI*, YU.M. LITVIN*, \\ S.YU. KUDZINOVSKY*, A.G. CHAKHOVSKOI**,T.E. FELTER***.
}

* Institute of Semiconductor Physics, 45 Prospekt Nauki, 252650 Kiev, UKRAINE. Fax:(380-44) 26583 42; E-mail:Evt@book.semicond.kiev.

** ECE Department, University of California, Davis, CA 95616, chakhovs@ece.ucdavis.edu

*** Lawrence Livermore national Laboratory, Livermore, CA felter@llnl.gov

\section{ABSTRACT}

In this presentation the electron field emission and electrical conductivity of the undoped and nitrogen doped DLC films have been investigated.

Undoped and nitrogen doped DLC films were grown by PE CVD from $\mathrm{CH}_{4}: \mathrm{H}_{2}$ and $\mathrm{CH}_{4}: \mathrm{H}_{2}: \mathrm{N}_{2}$ gas mixtures, correspondingly. During nitrogen doped DLC film/ deposition, the nitrogen content in ${ }^{\text {the }}$ gas mixture was varied within the range from 0 to $45 \%$. In-situ the gas-phase doping allowed us to deposit DLC films with different content of nitrogen were deposited under three different levels of gas pressure in the chamber: $0.2,0.6$ and 0.8 Torr.

The measurements of emission current from samples were performed in the vacuum system which could be pumped to a stable pressure of $10^{-6}$ Torr. The emission current was measured in the diode structure. The emitter-anode spacing $L$ was constant and equal to $20 \mu \mathrm{m}$.

The current - voltage characteristics of the Si field electron emission arrays covered with undoped and nitrogen doped DLC films show that at the beginning the threshold voltage $\left(V_{\text {th }}\right)$ remarkably increases 'with nitrogen content then $V_{\text {th }}$ is observed and to dere finally $V_{\text {th }}$ increases. Corresponding Fowler-Nordheim (F-N) plots follow F-N tunneling over a wide fretere The F-N plots were used for determination of the work functions, threshold voltage, field enhancement factors, effective emission areas.

For the qualitative explanation of experimental results we DLC film as a diamond-like ( $\mathrm{sp}^{3}$ - bonds) matrix with graphite-like inclusions in it.

\section{INTRODUCTION}

DLC films are very attractive for field emitter application. Previous results on DLC coating demonstrated very substantial enhancement of field emission due to the coating of the silicon tips with DLC films [1-5], but the influence of the preparation conditions of DLC films on their properties still has to be investigated. The doping with nitrogen strongly influences the emission properties of DLC films [6-8]. Nitrogen is 7 very suitable atom as a n-type dopant because the atomic size is similar to $\mathrm{C}$ and it is donor in diamond and DLC film.

In spite of the intensive investigations, the influence of the DLC film deposition conditions and nitrogen doping on DLC film properties is not well understood.

In this work, the electron field emission properties of silicon tip arrays coated with undoped and nitrogen doped DLC films are investigated. The properties of the DLC films strongly depend on the microstructure which can be varied by the deposition conditions. The influence of the DLC films deposition conditions on field electron emission is studied in detail. The correlation between the film properties and field emission characteristics is investigated. 


\section{EXPERIMENT}

\section{Cathode formation}

The arrays of silicon emitters tips were fabricated by forming the silicon points by wet chemical etching. The cathodes are formed on (100) Si n-type wafers $\left(N_{d}=10^{15} \mathrm{~cm}^{-3}\right)$ by patterning with $\mathrm{Si}_{3} \mathrm{~N}_{4}$ as masking material. The tip sharpening was performed by oxidation of the as-etched tips at $900^{\circ} \mathrm{C}$ in wet oxygen. After the oxidation, the oxide is removed in $\mathrm{HF}: \mathrm{H}_{2} \mathrm{O}$ solution. This sharpening technique allows the production of tips with a radius ${ }_{A}$ curvature of 10 $20 \mathrm{~nm}$. The height of the silicon tips was $4 \mu \mathrm{m}$. The arrays have been fabricated over areas of $8 \times 8$ $\mathrm{cm}^{2}$. The tip density was $2.5 \times 10^{5}$ tips $/ \mathrm{cm}^{2}$. The radii before and after DLC films deposition were estimated by scanning electron microscopy. the of silicon tip arrays by plasma enhanced chemical vapor deposition (PE CVD) methom a $\mathrm{CH}_{4}: \mathrm{H}_{2}: \mathrm{N}_{2}$ mixture. Nitrogen content in the gas mixture was varied within the range from 0 to con roll $_{\text {de }}$ 45\%. In-situ-gas-phase doping allowed nLC films with nitrogen DLC films were deposited under three different levels of gas pressure in the chamber: $0.2,0.6$ and 0.8 Torr. The substrates for deposition of DLC films were put directly on the cathode of diameter $200 \mathrm{~mm}$ which was cooled by water and capacitively connected to a 13.36 $\mathrm{MHz}$ generator. During the plasma decomposition experiments, RF bias voltage was about 1900 Volts. The DLC coatings were smooth enough and have reproducible properties from sample to sample under the same deposition conditions.

\section{Measurements}

The measurements of the emission current were performed in a vacuum system which could be pumped to stable pressure of $10^{-6}$ Torr. The emission current was measured in the ungated cathode-anode diode structure.

The emitter-anode spacing $\mathrm{L}$ was constant and equal to $20 \mu \mathrm{m}$. We fabricated a test diode by"sandwiching "of anode and cathode plates. A silicon wafer was used as the cathode and a molybdenum wire or quartzezplate coated with ITO (indium-tin oxide\$) was used as an anode. A 20 micron high fluorplast film spacer was used to keep the two plates separated from each other. The emission current-voltage characteristics were obtained with a current sensitivity of $5 \mathrm{nA}$ over a voltage range up to $1500 \mathrm{~V}$. A $0.56 \mathrm{M} \Omega$ resistor was placed in series with the cathode to provide short-circuit protection.

$$
\text { farbricotact, }
$$

After the tip array $\left(8 \times 8 \mathrm{~cm}^{2}\right)$ was completely fore wafer and mounted into the vacuum station. The control silicon emitter tip array (without coating) was dipped in a $5 \%$ HF solution for $20 \mathrm{~s}$ to remove the native oxide layer immediately before mounting in the HV system. The investigated cathode area for measurement was $5.5 \times 10^{-3} \mathrm{~cm}^{2}$ and it contained $1.4 \times 10^{3}$ tips.

Ceach

The resistivity of DLC films was determined from I-V curves of MIS structures at an electric field strength $10^{6} \mathrm{~V} / \mathrm{cm}$. The thickness and refractive index of the DLC films on flat silicon wafers was measured with the laser ellipsometer $(\lambda=632.8 \mathrm{~nm})$. To estimate the nitrogen content in DLC films, the Auger method was used.

\section{RESULTS AND DISCUSSION}


the

during

The flow of $\mathrm{N}_{2}$ in gas mixture $\mathrm{SiH}_{4}: \mathrm{H}_{2}: \mathrm{N}_{2}$ DLC film deposition was varied to control the $\mathrm{N}$ content in DLC film. Increasing of the $\mathrm{N}_{2}$ increas of the $\mathrm{N}$ content in DLC films and it depen fasmixture pressure (Fig.1). fow

The current - voltage characteristics of the Si field electron emission arrays covered with undoped and nitrogen doped DLC films are presented in Fig. 2a. At the beginning, the threshold voltage $\left(V_{t h}\right)$ remarkably increases with nitrogen content then decreasing of $V_{\text {th }}$ is observed and finally $\mathrm{V}_{\text {th }}$ increases. Corresponding Fowler-Nordheim (F-N) plots are shown in Fig. 2b. The curves follow F-N tunneling over a wide field range. The F-N plots were used for determination of the threshold (turn-on) yoltage, work functions, field enhancement cocfficients, and effective emission aread according to the procedure described in Refs.9-12. It is impossible to inde $p$. ent'y determine two parameters: the field enhancement coefficient $(\beta)$ and work function $(\Phi)$ from the Fowler-Nordheim plot alone. The field enhancement coefficients were calculated from the geometry of the emitting system according to

$$
\beta=(\mathrm{h} /(\mathrm{r}+\mathrm{d})) / \mathrm{L}
$$

where $r$ is the radius of the tip estimated with SEM, $h$ is the height of the tip, $d$ is the thickness of cooting
DLC film, and $L$ is the emitter-anode spacing. For the case of silicon tips without DLC the field enhancement coefficient was determined from the Fowler-Nordheim plot for silicon $(\Phi=4.15 \mathrm{eV})$. The good agreement between $\beta$ calculated from equation (1) for case $\mathrm{d}=0$ and determined from Fowler-Nordheim plot is observed.

The effective work function for different DLC film coatings were determined from the slope of Fowler-Nordheim plots (b) using the calculated $\beta$ coefficient. The relation of the work functions of two materials (silicon and silicon covered with DLC films) was used.

$$
\Phi_{1} / \Phi_{2}=\left(b_{1} \beta_{1} / b_{2} \beta_{2}\right)^{2 / 3}
$$

where $\Phi_{i}, \beta_{i}$ and $b_{i}$ are the work functions, field enhancement coefficients and curve slopes in the Fowler-Nordheim equation, respectively, and index $i=1$ for silicon tip ${ }_{\Lambda}$ and $i=2$ for the ones coated covered with DLC film. uncoated

The dependences of threshold voltage and effective work function on the $\mathrm{N}_{2}$ in gas mixture afe presented in Figs. 3, 4. For comparison, the threshold voltage and effective work function of Si tips without DLC coatings are shown. Nonmonoton ${ }^{\circ} \mathrm{c}$ dependences on $\mathrm{N}_{\text {the }}$ content are measured. A $A^{n}$ inc reate of $^{-}$effective work function is observed in the initial part of ${ }_{A}$ therve. A further increase of $N$ content causes the decrease of $\Phi$. At high $N_{2}$ concentration the growth of $\Phi$ is observed again. The lowest value of $\Phi=0.92 \mathrm{eV}$ was obtained for DLC films deposited at $\mathrm{N}_{2}=25 \%$ in the gas mixture. A significant influence of the gas pressure on effective work function is also observed. As can be seen from Figs.4a,b correlation exists in $V_{\text {th }}$ and $\Phi$ dependencies. This points out that emission efficiency is caused not only by ${ }_{\wedge}^{\text {effective work }}$ function but the DLC film's conductivity atso. as well. the

The, resistivity of the DLC film on $\mathrm{N}_{2}$ content in gas mixture dependence was also measured. The resistivity, with $\mathrm{N}_{2}$ content aw at the beginning with the a nd f decreasing is increases

An optical band gap of the DLC films has been measured by using spectroscopic ellipsometry. The band gap is changed significantly with $N$ content in DLC film. In case of nitrogen doped DLC film, the smallest value of $E_{\mathrm{g}}$ is observed (Fig.5). (the the

Values of the band gap reach up to $4 \mathrm{eV}$ at higher $\mathrm{N}_{2}$ content. Our experimental results concerning the influence of the nitrogen doping on DLC film properties are in agreement with data obtained by other authors $[6,7,9]$.

Nitrogen atoms in DLC films stabilize carbon atoms in $\mathrm{sp}^{3}$ sites with $\mathrm{C}-\mathrm{N}$ bond creation. At the same time, nitrogen is the donor-type impurity in diamond and DLC films. Ondoped DLC film shows p-type conductivity. Under low levels of nitrogen doping in DLC, the n-type donor impurity compensates the p-type. As a result the conductivity of DLC film is decreased. When 
the $\mathrm{N}$ content is less than 1.7 at \% the emission current is less than that of undoped DLC film, probably due to the higher resistance of compensated DLC film.

The continuous shift of Fermi level towards the conduction band occurs with $\mathrm{N}$ content in the film. This causes an increase in the emission current and a decrease of threshold voltage (see Fig.3). The effective work function decreases, but further growth of $\mathrm{N}$ content promotes the band gap increase (see Fig.4,5) due to the $\mathrm{sp}^{3}$ bond growth and, consequently, the effective work function is increased. As a result, the dependence of the effective work function on $N$ content has, minimum. According to medel of the DLC films as a diamond-like matrix with graphite-like inclusions in it, these films are not homogeneous material and have the thickness and spatial heterogeneity of their structure which is caused the deposition conditions. To characterize such films, we used the "effective" work function. by

The nonmonoton dependencies of $\mathrm{E}_{\mathrm{g}}$ (Fig.5) on nitrogen content in the gas mixture may be interpreted in the framework of a model taking into account the effect of nitrogen on the film structure. At low concentration, the nitrogen atoms fit into the film at $\mathrm{sp}^{2}$-clusters boundaries increasing the fraction of the disordered $\mathrm{sp}^{2}$-phase[10,11]. This, in turn, must result in $E_{g}$ decreasing, which is actually observed (See Fig 5). On further increasing the nitrogen content in the film, the excess nitrogen atoms begin to fit in between the $\mathrm{sp}^{2}$-clusters. This causes strain relaxation in the film and stimulates formation of $\mathrm{sp}^{3}$-coordinated carbon-hydrogen bonds. As this takes place, $\mathrm{E}_{\mathrm{g}}$ increases.

The relationship among work function, electron emission and conductivity should be studied further to clarify the emission mechanism of DLC films.

\section{CONCLUSION}

- We have studied the electron field emission from silicon tip arrays coated with undoped and nitrogen doped DLC films. The doping level was changed by varying the nitrogen content in gas mixture $\mathrm{CH}_{4}: \mathrm{H}_{2}: \mathrm{N}_{2}$ Nonmonoton dependences of effective work function, threshold voltage, resistivity and optical band gap on nitrogen content in DLC film are observed. The minimum effective work function was in case of $N_{2}=25 \%$ in thas mixture, and found to be 0.92 $\mathrm{eV}$. We proposed an explanation of the experimental results on electron field emission taking into account the work function, band gap and conductivity. Using a silicon tip array covered with undoped and in-situ nitrogen doped DLC films leads to increase of electron emission currents in comparison with uncoated arrays.

\section{ACKNOWLEDGMENTS}

The research described in this publication was made possible in part by Award UE1-316 of the U.S. Civilian Research and Development Foundation for the Independent States of the Former Soviet Union (CRDF). TEF supported by United Stats, Repaut ment of Energy under contract No, w-7405-ENG-48 at LLNL. REFERENCES

1. A.A. Evtukh, V.G. Litovchenko, R.I. Marchenko, B.N. Romanuyk in: MRS Spring Meeting (San-Francisco), Abstracts (1995) p.396.

2. S. Lee, Su. Lee, Sun. Lee, D. Jeon, in Proceedings of the $9^{\text {th }}$ IVMC'96, (1996) pp.283-287.

3. O. Groning, O.M Kuttel, P. Groning, L. Schlapbach, Appl. Surf. Sci. 111, 135 (1997).

4. V.G. Litovchenko, A.A. Evtukh, R.I. Marchenko, N.I. Klyui, V.A. Semenovich, Appl. Surf. Sci., 111, 213 (1997).

5. V.G. Litovchenko, A.A Evtukh, R.I. Marchenko, N.I. Klyui, and V.A. Semenovich, J. Micromech. Microeng. 7, 1 (1997). 
6. K.C. Park, J.H. Moon, J.G. Kim, S.J. Chung, M.H. Oh and J. Jang, in Proccedings of the $9^{\text {th }}$ IVMC'96, (1996) pp.263-267

7. E.J. Chi, J.Y.Shim, H.K. Baik, in Proceedings of the $11^{\text {th }}$ VMC'98, (1998) pp.204-205.

8. A.A. Evtukh, V.G. Litovchenko, N.I. Klyui, R.I. Marchenko, S.Yu. Kudzinovski, in Proccedings of the $11^{\text {th }}$ VMC'98, (1998) pp.232-233.

9. K.C. Park, J.H. Moon, S.J. Chung, J.H. Jung, B.K. Ju, M.H. Oh, W.I. Milue, M.K. Han, J. Jang, in Proccedings of the $9^{\text {th }}$ IVMC'96, (1996) pp.298-302.

10. F. Demichelis F., X.F. Rong, et. al., Diamond and Related Materials. 4(4), 361 (1995).

11. N.I. Klyui, B.N. Romanyuk, V.G. Litovchenko, B.N. Skarban, V.A. Mitus, V.A. Semenovich, S.N. Dub, Journal of CVD, 5, 305 (1997).

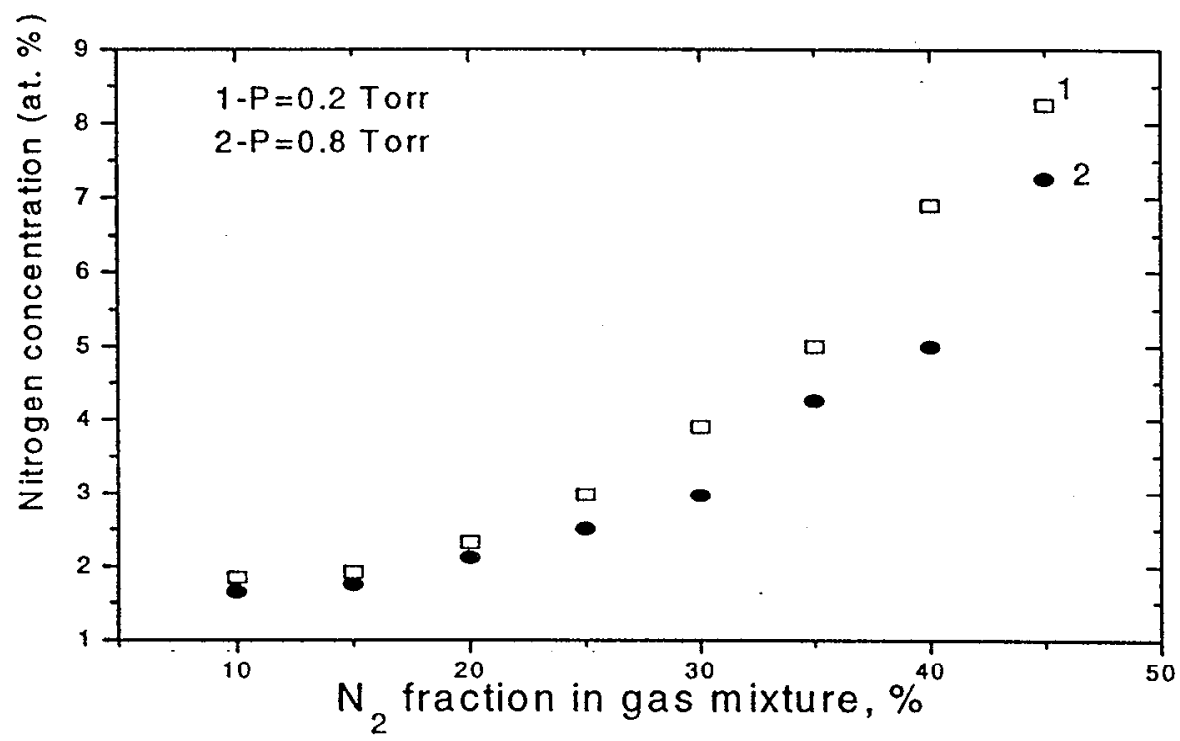

Fig.1. Nitrogen concentration in DLC film on nitrogen fraction in gas mixture dependences; $1-\mathrm{P}=0.2$ Torr; $2-\mathrm{P}=0.8$ Torr.
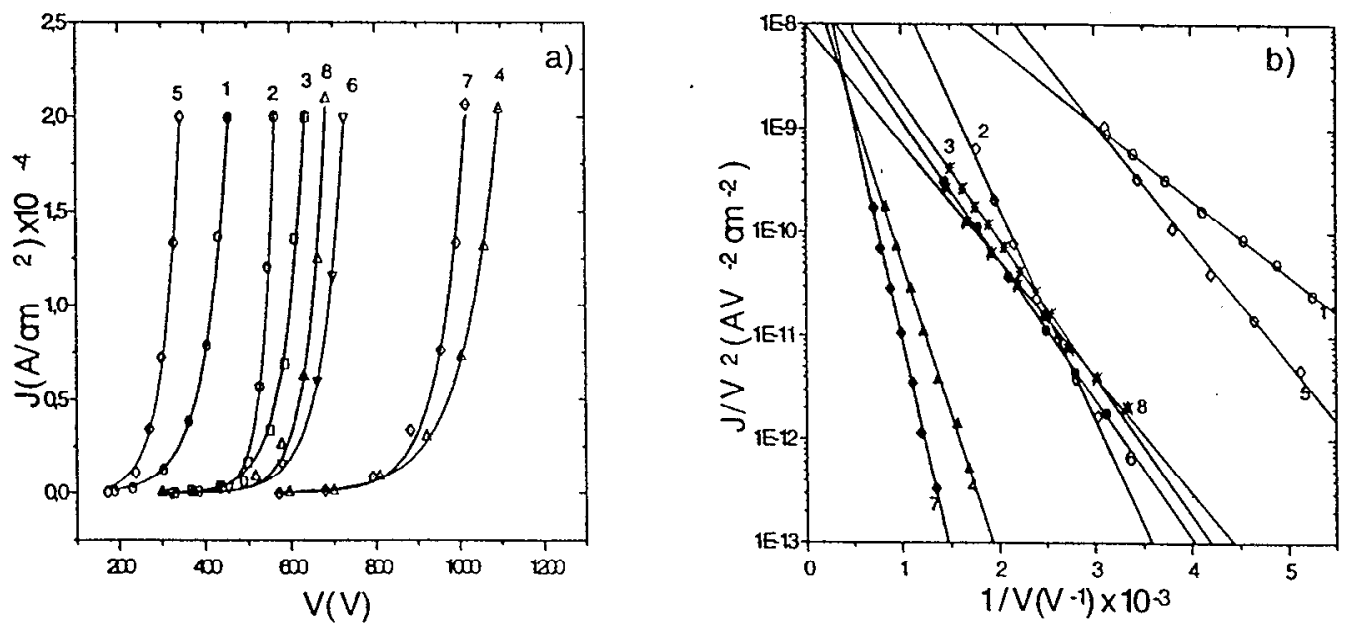

Fig.2. Current - voltage characteristics and corresponding Fowler-Nordheim plots of the Si tip arrays coated with undoped and gas phase doped DLC films: (1-8) Si tip arrays +DLC: $1-\mathrm{C}\left(\mathrm{N}_{2}\right)$ $-0 \% 2-5 \% ; 3-10 \% ; 4-15 \% ; 5-20 \% ; 6-25 \% ; 7-30 \% ; 8-35 \%$ ( $\mathrm{P}=0.8$ Torr, $\mathrm{C}\left(\mathrm{N}_{2}\right)-$ nitrogen content in gas mixture under PE CVD deposition). 


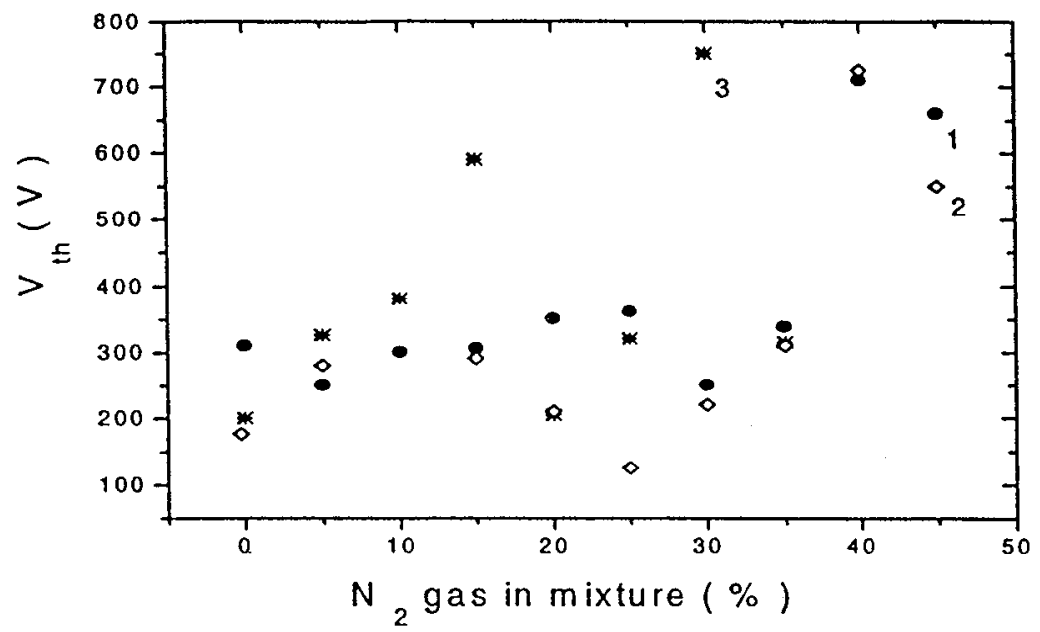

Fig 3. Threshold voltage under electron field emission from silicon tips+DLC films on nitrogen content in gas mixture dependences $(1-\mathrm{P}=0.2$ Torr, 2 - $\mathrm{P}=0.6$ Torr, $3-\mathrm{P}=0.8$ Torr )

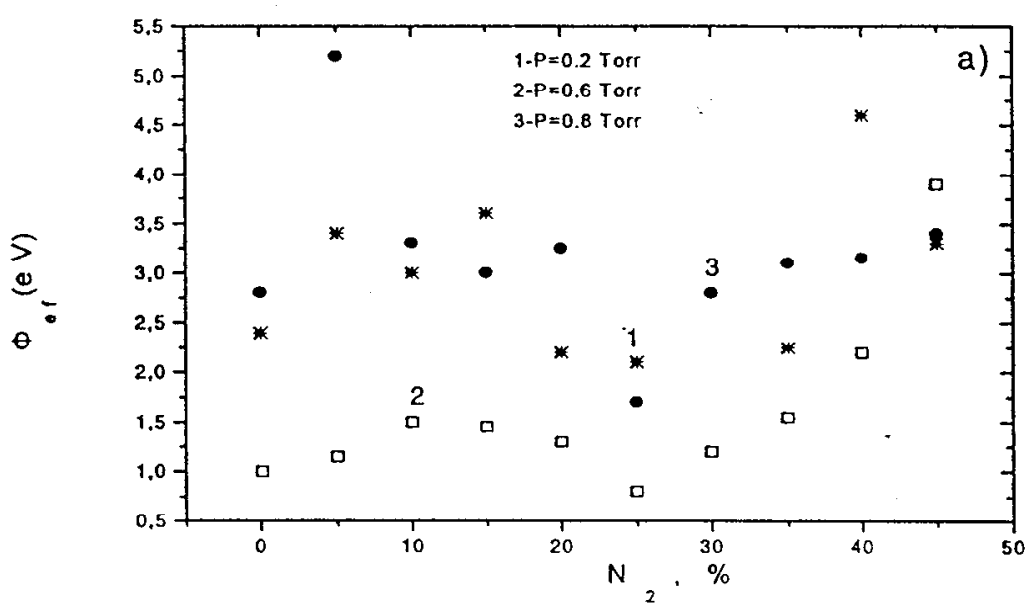

Fig 4 Effective work function under electron field emission from silicon tips+DLC films on nitrogen content in gas mixture dependences $(1-\mathrm{P}=.0 .2$ Torr, $2-\mathrm{P}=0.6$ Torr, $3-\mathrm{P}=0.8$ Torr $)$

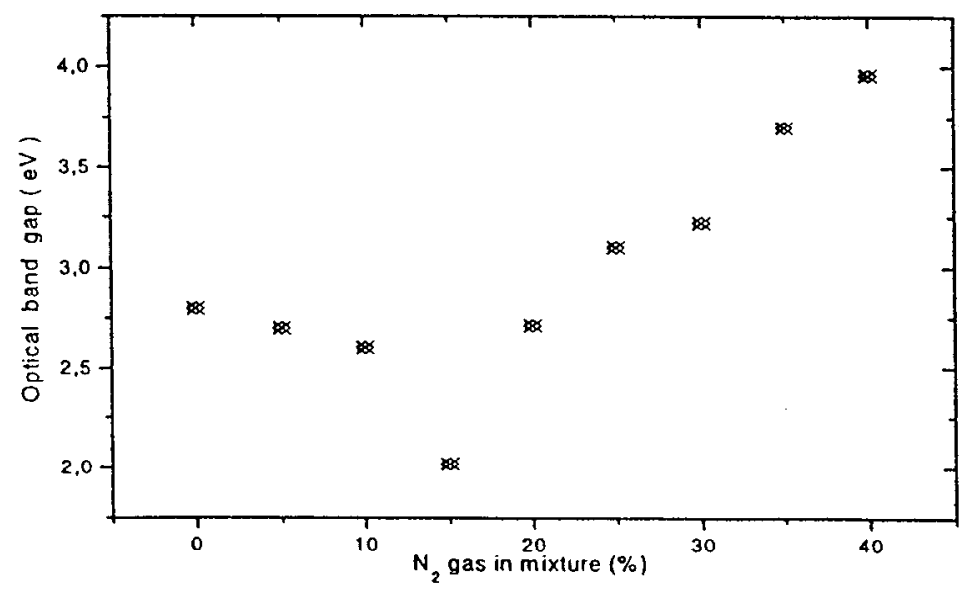

Fig.5. Optical band gap of DLC films on nitrogen content in gas mixture dependence ( $\mathrm{p}=0.8$ Torr) 